Research Article

\title{
Optimization Model of Carbon Footprint of Fresh Products in Cold Chain from the Energy Conservation and Emission Reduction Perspective
}

\author{
Bin Hu $\left(\mathbb{D},{ }^{1}\right.$ Bangtong Huang, ${ }^{1}$ Zheng Liu $\mathbb{D}^{1},{ }^{1}$ Hangxin Guo, ${ }^{1}$ Zihong Chen, ${ }^{2}$ and Lihua Shi ${ }^{1}$ \\ ${ }^{1}$ School of Management, Shanghai University of Engineering Science, Shanghai 201620, China \\ ${ }^{2}$ College of Engineering, Shantou University, Shantou 515041, China \\ Correspondence should be addressed to Zheng Liu; liuzheng960@163.com
}

Received 21 January 2021; Revised 5 March 2021; Accepted 2 April 2021; Published 16 April 2021

Academic Editor: Xiaobo Qu

Copyright (C) 2021 Bin Hu et al. This is an open access article distributed under the Creative Commons Attribution License, which permits unrestricted use, distribution, and reproduction in any medium, provided the original work is properly cited.

\begin{abstract}
The carbon footprint of the cold chain logistics system refers to the greenhouse gas emissions directly or indirectly caused in each link of the cold chain logistics activities. Because cold chain logistics is the main carbon emitter in the field of logistics, research on how to reduce carbon emissions in the field of cold chain logistics plays an important role in energy conservation and emission reduction. Based on the in-depth analysis of the carbon footprint of cold chain logistics, this paper introduces the distance coefficient and freshness parameters into the optimization model innovatively and uses the life cycle assessment method and input-output method to determine the calculation range of the carbon footprint of fresh products of each link in the cold chain logistics. The system calculates the carbon emissions generated by the production and operation activities of each place of origin, distribution center, retailer, and waste disposal during the circulation of fresh products. This paper establishes a carbon footprint optimization model to discuss how to balance carbon constraints and minimized costs. Through the analysis of the simulation results, from the perspective of the government and enterprises, corresponding countermeasures are put forward to more effectively achieve the goal of energy conservation and emission reduction and guide the cold chain logistics industry to sustainable development.
\end{abstract}

\section{Introduction}

The vigorous development of online sales is slowly changing people's habit of buying fresh food: from offline traditional markets to large-scale fresh food supermarkets or online stores specializing in fresh food, which led to the larger demand for cold chain logistics in society. The total scale of China's cold chain logistics market in 2019 is expected to reach 339.12 billion yuan, an increase of 50.52 billion yuan over 2018 and an increase of $17.60 \%$ year-on-year. On the other hand, as one of the important factors affecting the global climate, carbon emissions have always been a green indicator of concern. In the cold chain transportation industry, if we consider carbon emissions, minimizing overall costs becomes a question worth discussing. Taking the particularity of the timeliness requirements of fresh products during transportation into account, many relevant experts at home and abroad have conducted research on the carbon footprint emissions of cold chain logistics in order to meet the market demand while using low-carbon cold chain logistics operation as much as possible.

Recently, as for the cold chain logistics industry, the limitation of carbon emissions is closely related to the development of the industry. Under the existing technical conditions, fossil fuels cannot be completely replaced with clean energy during transportation. It is very important to explore the key factors that affect carbon emissions during transportation. This paper established a carbon footprint optimization model to discuss the relationship between the speed of refrigerated truck, the expectation rate of freshness, the distance coefficient, and carbon emission. By studying the relationship between these key variables and the carbon footprint and total cost, we hope to find ways to control carbon emissions, reduce the total cost of 
enterprises, and benefit the development of the cold chain logistics industry.

\section{Literature Review}

With the increase of people's awareness of environmental protection and increasingly serious environmental problems, the value of the reverse supply chain becomes more and more important [1]. In terms of the development status of cold chain logistics, Chen and Huang investigated the development of cold chain logistics business of 111 fresh agricultural product e-commerce websites and conducted research on the related content of cold chain logistics services. In the end, they put forward countermeasures in terms of policy and equipment technology [2]. From the perspective of literature review, Wang et al. compared relevant researches on carbon footprint and carbon emission factors at home and abroad under different research methods. They summarized the current research status at home and abroad and looked forward to the future research direction [3]. Tseng et al. used ant colony optimization algorithm to establish a path optimization model of cold chain logistics considering carbon emission cost. They have proved that this model can reduce the total cost and carbon emissions of logistics enterprises. [4]. Ke started from the needs of ecological development, studied and analyzed the status quo and problems of cold chain logistics of agricultural products, and proposed ideas for optimization problems [5]. Hu et al. considered the combined strategy of repurchase and subsidy at the same time to achieve the dual goals of emission reduction and economic benefits [6]. Lo-Iacono-Ferreira et al. took the cold chain logistics of fruits and vegetables in Spain as an example, analyzed in detail the differences in carbon emissions produced by different links in the whole process of cold chain logistics, and conducted sensitivity analysis on transportation distances [7]. Kim et al. explored the relationship between carbon emissions in multimodal transport and those in trucks only and developed decision support tools to simplify the freight network [8]. Qin et al. built a carbon trading mechanism model based on cyclic evolutionary genetic algorithm to calculate the cost of carbon emissions. They also studied the sensitivity of carbon prices to carbon emissions and customer satisfaction [9].

In order to solve the multiobjective problem, Wang et al. established a double objective mathematical model of cold chain logistics network based on economic, social, and environmental benefits and proposed a multiobjective hyperheuristic optimization framework including four selection strategies and four acceptance criteria [10]. Beretta et al. focused on the conflict between fresh food consumption and energy consumption. They used life cycle method and modern simulation technology to propose a model to find the optimal balance point [11]. Bortolini and Marco studied the comprehensive optimization of cost, delivery time, and carbon footprint emissions as the goal. They used the cold chain distribution data of fresh food retailers in Europe as an example from Italy to develop a multidimensional network model of fresh food supply chain [12]. Tian et al. built a newsboy model based on carbon footprint related theories for carbon restriction and trading mechanisms. They studied and analyzed the impact of carbon restrictions on economic activities and the volume of newsboy orders in the traditional newsboy model [13].

In the field of transportation, Liu et al. studied the impact of price levels on urban public transportation and provided a basis for decision-making in the market pricing of bus companies by constructing a personalized pricing model [14]. Hu et al. investigated the trade-off between energy consumption and food loss after the expansion of cold chain logistics from the perspective of carbon emissions and constructed a nonlinear optimization framework to determine the best balance point under constant final demand [15]. Moncer et al. studied how to reduce comprehensive costs including carbon tax and operation for bulk transportation through classical inventory model accounting and effective integration of scattered goods [16]. Yao and Zhang combined the characteristics of the latest Internet of Things technology and used Matlab to solve the model to calculate the path optimization method with the smallest total cost, which provides an effective tool for enterprise logistics and distribution decision-making [17]. In the field of supply chain risk, Liu and $\mathrm{Xu}$ et al. studied the impact of risk attitudes on dual-channel supply chain systems [18]. Liu et al. used dual theory and variational inequality to prove that increasing the proportion of environmental protection target weight can improve the environmental performance and economic benefit of enterprises. They solved the optimal solution of the double objective function constructed by carbon emission and enterprise profit [19]. Wei et al. constructed a differential game model based on carbon trading. By using this model, it is possible to carry out research on energy conservation and emission reduction in the supply chain and propose corresponding optimal development strategies [20]. Efthymiou. et al. established a multiobjective decision-making model, established a multiobjective function, which combines cost and carbon emissions, and verified that cost reduction and carbon emission reduction can meet the requirements at the same time [21]. Battini et al. studied the sensitivity analysis of the change of carbon price of the model based on the cost and carbon emission multiobjective function. They put forward the conclusion that low-carbon prices cannot stimulate sustainable purchasing behavior [22]. In the field of path planning, Liu et al. built an integer programming model to study the route optimization problem of cold chain transportation of fresh products and compared the advantages and disadvantages of genetic algorithms and hybrid algorithms [23].

Therefore, based on previous studies, existing studies have explored the relationship between carbon footprint and economic activities for carbon footprint or carbon restriction and trading mechanisms. Scholars have done detailed research in the fields of defining the carbon footprint accounting boundary of cold chain logistics and the relationship between carbon footprint and cost and delivery time. The above researches focused on the calculation of the carbon footprint of specific foods or the optimization of cold chain logistics paths and profit distribution under the 
conditions of carbon footprint. However, the system construction of the carbon footprint optimization model of cold chain logistics was rarely involved. They also did not explore how the cold chain logistics carbon footprint will be affected if there is a requirement of freshness in the system's terminal marker. Therefore, based on previous studies, this paper focuses on exploring the role of freshness in the carbon footprint model of cold chain logistics and the relationship between it and the cost and carbon footprint.

\section{Problem Description and Model Hypothesis}

Since fresh products have strict requirements on temperature, humidity, and delivery timeliness, it will inevitably consume more energy and generate a lot of carbon emissions during transportation. Therefore, cold chain logistics has become a major carbon emitter in the logistics industry. The focus problem of the logistics industry is how to reduce the carbon emissions of fresh products in cold chain logistics. This paper not only adds a multimodal transportation scenario that combines rail and road transport on the basis of the traditional cold chain logistics carbon footprint system but also considers freshness parameter as an important factor affecting sales results and establishes a carbon footprint model of cold chain logistics with the goal of optimal overall cost. Because the cold chain transportation industry has stringent requirements for the freshness of fresh products. The freshness of fresh products when it reaches the end retail market is directly related to the carbon footprint of the whole transportation system. In order to calculate the carbon footprint more accurately, the freshness parameter must be considered. The paper adopts the classic three-level network of origin-distribution center-retailer as the main research object and calculates the cost and carbon emissions of each link to find the optimal solution.

According to the analysis based on the life cycle assessment method, for the specific product of fresh food, the carbon footprints of origin, transshipment, distribution centers, retailers, and waste disposal are all included in the carbon footprint of the cold chain logistics system constructed in this paper. The detailed links of the supply chain are shown in Figure 1.

In order to facilitate calculation and simplify the model, the following assumptions are made for the overall model:

(1) The information of fresh products on the place of origin, distribution center, and retailers is easily accessible, and the demand of retail market for fresh products is clear.

(2) The distance data between the transportation nodes in the model is clear.

(3) The entire transportation process of fresh products adopts cold chain transportation and the temperature of it is constant. It is assumed that when the transportation speed is constant, the carbon footprint and freshness parameter are only related to time, without considering influences of other factors.
(4) The delivery volume should ensure that there is no shortage of fresh products in the retail market to meet customers' needs.

(5) The objective function of the model considers both the total economic cost and the carbon footprint cost.

\section{Carbon Footprint Optimization Model of Fresh Products of Cold Chain Logistics}

4.1. Definition of Variables and Parameters Settings. According to the life cycle assessment method, the carbon footprint calculation boundary of fresh products of cold chain logistics is defined. The supply chain of fresh products is roughly divided into four links: the place of origin, the distribution center, the retailer, and the waste disposal. The carbon footprint is subdivided into these four links for accounting. The objective function is divided into two parts: the economic cost of the fresh products' supply chain and the environmental cost of the fresh products' supply chain. The weighted average method is used to put two parts in the same measurement standard system. Based on the above principles, an optimized system model is established to discuss how to minimize economic costs under the constraints of carbon footprint. The definitions of variables and parameters used in the model are shown in Table 1.

4.2. Constraints. When the distribution center $j$ is in operation, the fresh products are transported from the place of origin $i$ to the distribution center $j$; then

$$
X_{i j} \leq Z_{j}, \quad \forall i \in I, j \in J .
$$

Fresh products can be shipped from different places of origin to different distribution centers, so multiple transportation models can be built:

$$
\sum_{i} X_{i j} \geq Z_{j}, \quad \forall j \in J
$$

When distribution center $j$ is in operation and retailer $k$ has market demand,

$$
X_{j k} \leq Z_{j}, \quad \forall j \in J, k \in K .
$$

Fresh products are delivered from different distribution centers to place $k$ :

$$
\sum_{j} X_{j k} \geq 1, \quad \forall k \in K .
$$

The turnover between the place of origin, distribution center, and retailer should be within their respective capabilities:

$$
\begin{aligned}
& Q_{i j}^{\min } X_{i j} \leq Q_{i j} \leq Q_{i j}^{\max } X_{i j}, \quad \text { ct } \quad Q_{i j} \in N, \forall i \in I, j \in J, \\
& Q_{j k}^{\min } X_{j k} \leq m_{j k} L C \leq Q_{j k}^{\max } X_{j k}, \quad \forall j \in J, k \in K .
\end{aligned}
$$

For the value of $Z_{d}$ decision variable, $Z_{d}$ is 0 - 1 variable, $d_{i j} \geq \beta$, then $Z_{d}=0, d_{i j} \leq \beta$, then $Z_{d}=1$ : 


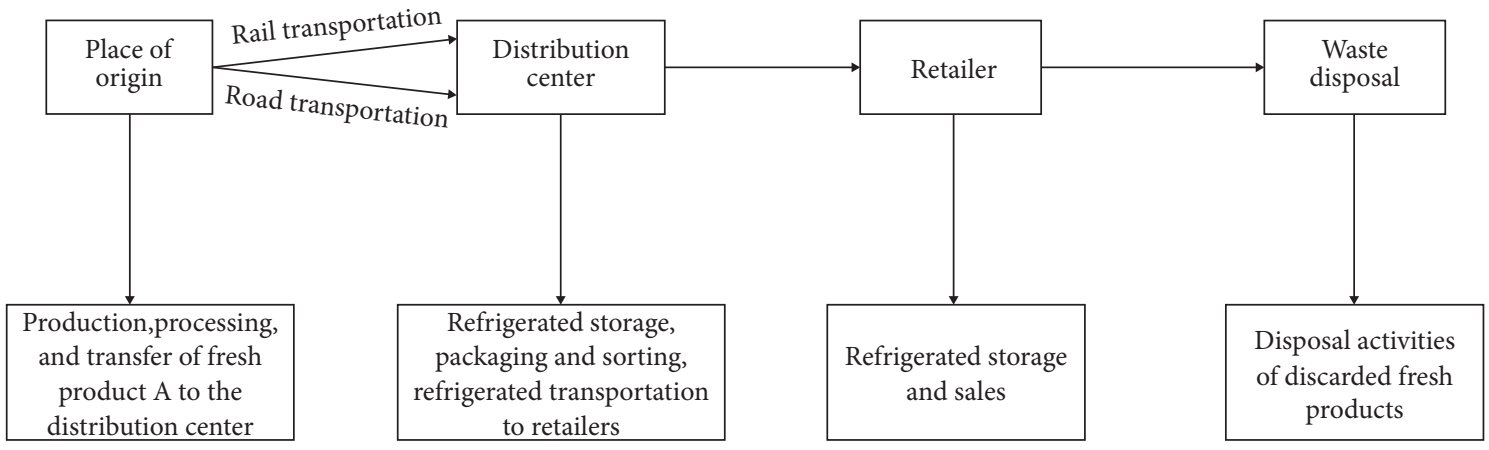

FIgURE 1: The main carbon footprint links of fresh product A in cold chain logistics.

TABle 1: Parameters' settings and interpretation.

\begin{tabular}{|c|c|}
\hline $\begin{array}{l}\text { Variables and } \\
\text { parameters }\end{array}$ & Interpretation of variables and parameters \\
\hline$I=\{1, \ldots \ldots, i\}$ & $I$ is a subset of place of origin $i$ \\
\hline$J=\{1, \ldots \ldots, j\}$ & $J$ is a subset of distribution center $j$ \\
\hline$K=\{1, \ldots \ldots, k\}$ & $K$ is a subset of retailer $k$ \\
\hline$P_{i}$ & The output of place of origin $i, \mathrm{~kg}$ \\
\hline$C_{1}$ & The unit production cost of fresh products at place of origin $i$, yuan $/ \mathrm{kg}$ \\
\hline$D_{j}$ & The cargo handling capacity of distribution center $j, \mathrm{~kg}$ \\
\hline$C_{2}$ & The unit cost of products handled by the distribution center, yuan $/ \mathrm{kg}$ \\
\hline$C_{3}$ & Fixed cost of the distribution center,yuan \\
\hline$Q_{i j}$ & Distribution volume from place of origin to distribution center, $\mathrm{kg}$ \\
\hline$Q_{j k}$ & Distribution volume from distribution center to retailer, $\mathrm{kg}$ \\
\hline$R_{k}$ & Demand of retailer market, $\mathrm{kg}$ \\
\hline$C_{i_{i}}^{G}$ & The unit freight for road transportation from the place of origin to the distribution center, yuan/kg \\
\hline$C_{i j}^{l_{i}}$ & The unit freight for railway transportation from the place of origin to the distribution center, yuan/kg \\
\hline$\beta$ & $\begin{array}{c}\text { The distance coefficient from the place of origin to the distribution center. The value of } \beta \text { can be } 400,500 \text {, or } 600 \text {, } \\
\text { which indicates the distance }\end{array}$ \\
\hline$C_{4}$ & The unit freight from distribution center to retailer, yuan $/ \mathrm{kg}$ \\
\hline$d_{i j}$ & Transportation distance from the place of origin to distribution center, km \\
\hline$d_{j k}$ & Transportation distance from distribution center to retailer, $\mathrm{km}$ \\
\hline$C_{f}^{n}$ & Fixed cost of refrigerated truck, yuan/vehicle \\
\hline$m_{j k}$ & The number of refrigerated trucks required for the transportation from the distribution center to the retailer \\
\hline$t_{j k}$ & The transportation time from the distribution center to the retailer, $h$ \\
\hline$V$ & Speed of refrigerated truck, $\mathrm{km} / \mathrm{h}$ \\
\hline$L C$ & Actual load capacity of refrigerated truck, $\mathrm{kg}$ \\
\hline$C_{5}$ & The unit disposal cost of the retailer for dealing with spoiled fresh products, yuan $/ \mathrm{kg}$ \\
\hline$T_{s}$ & The carbon footprint of fresh products during the production process, $\mathrm{kgCO}_{2}$ \\
\hline$T_{g}$ & $\begin{array}{c}\text { The carbon footprint of each unit of products during the road transportation from the place of production to the } \\
\text { distribution center, } \mathrm{kgCO}_{2}\end{array}$ \\
\hline$T_{t}$ & $\begin{array}{c}\text { The carbon footprint of each unit of products during the railway transportation from the place of production to } \\
\text { the distribution center, } \mathrm{kgCO}_{2}\end{array}$ \\
\hline$T_{p}$ & The carbon footprint of unit product processing in the distribution center, $\mathrm{kgCO}_{2}$ \\
\hline$T_{v}^{P}$ & The carbon footprint of unit product of a refrigerated truck at a speed of $\mathrm{m} \mathrm{km} / \mathrm{h}, \mathrm{kgCO}_{2}$ \\
\hline $\mathrm{C}_{\mathrm{CO}_{2}}$ & The tax rate of the supply chain of fresh products' carbon footprint, yuan $/ \mathrm{kg}$ \\
\hline$\lambda^{c_{2}}$ & Freshness parameter of fresh products over time, \% \\
\hline$\theta$ & The corrosion rate of fresh products over time, $\%$ \\
\hline W & The hourly wage of refrigerated truck driver,yuan \\
\hline$\left[E_{k}, L_{k}\right]$ & The time window of retailer $k$ \\
\hline$R T_{k}$ & The moment when the vehicle arrives at retailer $k$ \\
\hline$C_{6}$ & The cost per unit time, yuan/h \\
\hline$\delta$ & Penalty cost coefficient for late receipt \\
\hline$\varepsilon$ & Waiting cost coefficient for early arrival \\
\hline$Z_{d}$ (decision variables) & The 0 - 1 decision variable determined by $\beta, d_{i j} \geq \beta, Z_{d}=0, d_{i j}<\beta, Z_{d}=1$ \\
\hline$X_{i j}$ (decision variables) & Contact status of the place of origin and distribution center \\
\hline$X_{j k}($ decision variables $)$ & Contact status of the distribution center and the retailer \\
\hline$Z_{j}$ (decision variables) & The status of the distribution center; when in operation, $X_{i j}, X_{j k}$, and $Z_{j}$ are 1 ; otherwise, $X_{i j}, X_{j k}$, and $Z_{j}$ are 0 \\
\hline
\end{tabular}




$$
\frac{d_{i j}-\beta}{Z_{d}-0.5} \leq 0
$$

If the output of the place of origin $i$ is equal to the shipping volume, the inventory of the place of origin is 0 :

$$
\begin{aligned}
P_{i}^{\min } & \leq P_{i} \leq P_{i}^{\max }, & & P_{i} \in N, \forall i \in I, \\
P_{i} & =\sum_{j} Q_{i j}, & & \forall j \in J .
\end{aligned}
$$

For the distribution center, not only is the inventory less than or equal to the amount of products shipped from the place of origin and not higher than its own inventory level but also it meets the inventory demand:

$$
\begin{array}{rlrl}
D_{j}^{\min } \leq D_{j} \leq D_{j}^{\max }, & & D \in N, \forall j \in J, \\
D_{j} & =\sum_{j} Q_{i j}, & & \forall i \in I, \\
\sum_{k} m_{j k} L C \leq D_{j} Z_{j}, & & \forall j \in J .
\end{array}
$$

According to the Arrhenius formula, the corrosion rate equation is

$$
\theta=H e^{\left(-E_{a} / R T\right)} .
$$

When the temperature does not change, $E_{a}$ is a constant, and $\theta$ is also a constant. It can be obtained from the research of Jiang and Yang [24] that the freshness function $\lambda$ is

$$
\lambda=e^{-\theta t t_{j k}}, \quad \theta \in N, t_{j k} \in N, \forall j \in J, k \in K .
$$

Because fresh products are inevitably corroded during the circulation process, in order to meet the market demand, the supply volume should exceed the market demand:

$$
\sum_{j} m_{j k} L C \lambda \geq R_{k}, \quad \forall k \in K .
$$

If a refrigerated truck keeps driving at a constant speed during transportation, there is a functional relationship between its speed and carbon emissions:

$$
T_{v}=a\left(\frac{d_{j k}}{V}\right)^{2}+b V+c, \quad \forall j \in J, k \in K
$$

In the formula, $a, b$, and $c$ are constants, and other constraints are

$$
Q_{i j} \geq 0, \quad \forall i \in I, j \in J ; m_{j k} \geq 0 \text {, 且 } m_{j k} \in N, \forall j \in J, k \in K \text {. }
$$

Assuming that the starting time point of the vehicle from the distribution center is 0 , there is

$$
R T_{k}=\frac{d_{j k}}{V}, \quad \forall j \in J, k \in K .
$$

4.3. Establishment of the Carbon Footprint Model. When constructing an ideal cold chain logistics system, the total cost and carbon footprint cannot be considered separately. Instead, the total economic cost of the system and the carbon footprint should be organically combined, and the original multiobjective function should be transformed into a singleobjective function to find the optimal solution to the problem. The key to this transformation is to use the carbon tax price $C_{\mathrm{CO}_{2}}$ as a decision variable and integrate the total economic cost of the cold chain logistics system and the cost of carbon emissions. The carbon footprint of the entire life cycle of fresh products, such as production, transshipment, distribution, and disposal, is converted into social environmental costs to establish a unified measurement standard system. Based on this consideration, the established carbon footprint model is 
$\min$

$$
\begin{aligned}
F & =\sum_{i \in I} C_{1} P_{i}+\sum_{j \in J} C_{3} Z_{j}+\sum_{j \in J} C_{2} D_{j}+\sum_{j, k} C_{f} m_{j k}+\sum_{i, j}\left[Z_{d} Q_{i j} C_{i j}^{G}+\left(1-Z_{d}\right) Q_{i j} C_{i j}^{T}\right]+\sum_{j, k} m_{j k} C_{4} d_{j k} \\
& +\left[\sum_{i \in I} T_{s} P_{i}+\sum_{j \in J} T_{p} D_{j}+\sum_{i, j}\left[Z_{d} d_{i j} Q_{i j} T_{g}+\left(1-Z_{d}\right) d_{i j} Q_{i j} T_{t}\right]+\sum_{j, k} d_{j k} T_{v} m_{j k}+\sum_{w q e} C_{w} I C_{c o_{2}}\right. \\
& +\sum_{j, k} t_{j k} m_{j k} W+\sum_{k}\left[C_{5} m_{j k} L C(1-\lambda)\right]+C_{6}\left(\sum_{k} \delta\left(\max \left(0, R T_{k}-L_{k}\right)\right)+\sum_{k} \varepsilon\left(\max \left(0, E_{k}-R T_{k}\right)\right)\right)
\end{aligned}
$$

$$
\begin{aligned}
& \left\{\begin{array}{l}
X_{i j} \leq Z_{j}, \forall i \in I, j \in J ; \\
\sum_{i} X_{i j} \geq Z_{j}, \forall j \in J ; \\
X_{j k} \leq Z_{j}, \forall j \in J, k \in K ; \\
\sum_{j} X_{j k} \geq 1, \forall k \in K ;
\end{array}\right. \\
& Q_{i j}^{\min } X_{i j} \leq Q_{i j} \leq Q_{i j}^{\max } X_{i j}, Q_{i j} \in N, \forall i \in I, j \in J \\
& Q_{j k}^{\min } X_{j k} \leq m_{j k} L C \leq Q_{j k}^{\max } X_{j k}, \forall j \in J, k \in K ; \\
& \frac{d_{i j}-\beta}{Z_{d}-0.5} \leq 0 \\
& P_{i}^{\min } \leq P_{i} \leq P_{i}^{\max }, P_{i} \in N, \forall i \in I \\
& P_{i}=\sum_{j} Q_{i j}, \forall j \in J \\
& D_{j}^{\min } \leq D_{j} \leq D_{j}^{\max }, D_{j} \in N, \forall j \in J \\
& D_{j}=\sum_{i} Q_{i j}, \forall i \in I \\
& \sum_{k} m_{j k} L C \leq D_{j} Z_{j}, \forall j \in J \\
& \sum_{j} m_{j k} L C \lambda \geq R_{k}, \forall k \in K \\
& Q_{i j} \geq 0, \forall i \in I, j \in J \\
& m_{j k} \geq 0, \text { 且 } m_{j k} \in N, \forall j \in J, k \in K .
\end{aligned}
$$$$
\text { s.t. }
$$ 


\section{Simulation and Result Analysis}

5.1. Simulation Problem Description. Fresh product A is a kind of food that has a wide range of needs, which must be transported in refrigeration during distribution. The fresh product is sensitive to the freshness level, and the waste disposal cost is high. Fresh product A has a complete omnichannel logistics network which includes 4 parts: production, transport, processing, and distribution, in the B city group, which can effectively reflect the cold chain logistics model of fresh product $\mathrm{A}$. The cold chain logistics system of fresh product A is assumed to be composed of 3 places of origin, 3 distribution centers, and 4 retailers. The parameter data are shown in Tables $2-4$.

According to the basic requirements of the model mentioned above, it is assumed that the production, distribution, demand, and other data of 3 places of origin, 3 distribution centers, and 4 retailers are clear and easy to obtain, as shown in Tables $2-4$. The relevant data such as the transportation volume, freight, and distance from the place of origin to the distribution center and that from the distribution center to the retailer are shown in Tables 5 to 7. The values of the distance from the origin to the distribution center and that from the distribution center to the retailer are based on the actual situation. Generally speaking, in order to deliver fresh products to the terminal retail market faster, the location of the distribution center will consider the distance as close as possible from retailers.

According to the "China Carbon Tax Framework Design Report," the carbon tax rate in 2020 is 40 yuan/t, which means that the carbon footprint cost $C_{c o}$ is 0.04 yuan $/ \mathrm{kg}$. The refrigerated vehicle weight is assumed to be $4 \mathrm{t}$, that is, $\mathrm{LC}=4 \mathrm{t} /$ vehicle, and the fixed cost of each refrigerated vehicle is 4000 yuan. Due to the constant temperature of refrigerated trucks in cold chain distribution, the corrosion rate $\theta=0.1$, and the unit cost of the retailer to deal with the corrupted fresh products is 2 yuan $/ \mathrm{kg}$. Due to the constant temperature of refrigerated trucks in cold chain distribution and transportation, the corrosion rate is 0.1 . The retailer's unit cost for handling spoiled fresh products is 2 yuan $/ \mathrm{kg}$. The driver's salary $W=20$ yuan $/ \mathrm{h}$. According to the data from China Emissions Trading Network, the carbon footprint per unit product of road transportation and railway transportation from the place of origin to the distribution center is 0.0864 and 0.03016 . The distance of $600 \mathrm{~km}$ starting from Shanghai can cover most areas of Zhejiang Province, Jiangsu Province, and Anhui Province. So, the value of $\beta$ is 600 . The relationship between the speed of refrigerated trucks and the carbon footprint is shown in Table 8 .

Each retailer $k$ has a time window to set the time period for receiving goods. Delivery vehicles should be arranged to meet the customer's time window as much as possible, thereby reducing the increased costs due to late or early arrival. This part of the cost incurred can be expressed by the following formula: $C_{t}=C_{6}\left(\sum_{k} \delta\left(\max \left(0, R T_{k}-L_{k}\right)\right)+\right.$ $\left.\sum_{k} \mathcal{E}\left(\max \left(0, E_{k}-R T_{k}\right)\right)\right)$. Since fresh products have high requirements for timeliness, the time window of retailer $k$ is set to $[1.5,2]$ and the penalty cost coefficient $\delta$ of delayed
TABLE 2: Reference data of production capacity and cost of each place of origin.

\begin{tabular}{lcc}
\hline Origin category & Production capacity $(\mathrm{kg})$ & Unit cost (yuan/kg) \\
\hline$I_{1}$ & $0 \sim 35000$ & 1.80 \\
$I_{2}$ & $0 \sim 12700$ & 1.75 \\
$I_{3}$ & $0 \sim 73500$ & 2.00 \\
\hline
\end{tabular}

TABLE 3: Reference data of each distribution center.

\begin{tabular}{lccc}
\hline $\begin{array}{l}\text { Distribution } \\
\text { center }\end{array}$ & $\begin{array}{c}\text { Delivery } \\
\text { capacity }(\mathrm{kg})\end{array}$ & $\begin{array}{c}\text { Fixed cost } \\
\text { (yuan) }\end{array}$ & $\begin{array}{c}\text { Unit processing } \\
\text { cost (yuan/kg) }\end{array}$ \\
\hline$J_{1}$ & $45000 \sim 70000$ & 50000 & 0.025 \\
$J_{2}$ & $25000 \sim 45000$ & 66600 & 0.045 \\
$J_{3}$ & $20000 \sim 60000$ & 69000 & 0.040 \\
\hline
\end{tabular}

TABLE 4: The status of market demand.

\begin{tabular}{lcccc}
\hline Retailer & $K_{1}(\mathrm{~kg})$ & $K_{2}(\mathrm{~kg})$ & $K_{3}(\mathrm{~kg})$ & $K_{4}(\mathrm{~kg})$ \\
\hline Market demand & 12000 & 25000 & 10000 & 15000 \\
\hline
\end{tabular}

TABLE 5: Transportation volume between place of origin and distribution center.

\begin{tabular}{lccc}
\hline Place of origin & \multicolumn{3}{c}{ Distribution center } \\
& $J_{1}(\mathrm{~kg})$ & $J_{2}(\mathrm{~kg})$ & $J_{3}(\mathrm{~kg})$ \\
\hline$I_{1}$ & 15000 & 12000 & 8000 \\
$I_{2}$ & 5000 & 4700 & 3000 \\
$I_{3}$ & 30000 & 20000 & 23500 \\
\hline
\end{tabular}

TABLE 6: Distances corresponding to different transportation paths in the system.

\begin{tabular}{lccccccc}
\hline Origin & $J_{1}$ & $J_{2}$ & $J_{3}$ & $K_{1}$ & $K_{2}$ & $K_{3}$ & $K_{4}$ \\
$(\mathrm{~km})$ & $(\mathrm{km})$ & $(\mathrm{km})$ & $(\mathrm{km})$ & $(\mathrm{km})$ & $(\mathrm{km})$ & $(\mathrm{km})$ \\
\hline$I_{1}$ & 800 & 500 & 300 & - & - & - & - \\
$I_{2}$ & 750 & 460 & 380 & - & - & - & - \\
$I_{3}$ & 700 & 550 & 710 & - & - & - & - \\
$J_{1}$ & - & - & - & 200 & 160 & 100 & 120 \\
$J_{2}$ & - & - & - & 180 & 100 & 110 & 140 \\
$J_{3}$ & - & - & - & 110 & 120 & 130 & 140 \\
\hline
\end{tabular}

TABle 7: Unit transportation cost from distribution center to retailer.

\begin{tabular}{lcccc}
\hline $\begin{array}{l}\text { Distribution } \\
\text { center }\end{array}$ & \multicolumn{4}{c}{ Retailer } \\
& $K_{1}$ & $K_{2}$ & $K_{3}$ & $K_{4}$ \\
(yuan/km) & $($ yuan $/ \mathrm{km})$ & $($ yuan $/ \mathrm{km})$ & $($ yuan $/ \mathrm{km})$ \\
\hline$J_{1}$ & 0.85 & 0.90 & 1.95 & 1.78 \\
$J_{2}$ & 0.96 & 1.45 & 2.16 & 1.72 \\
$J_{3}$ & 0.76 & 1.25 & 2.61 & 2.35 \\
\hline
\end{tabular}

harvest is 50 . The waiting cost coefficient $\varepsilon$ for early arrival is 40. The unit time cost $C_{6}$ takes the value 3 .

5.2. Model Simulation and Analysis. Through modeling analysis, it can be obtained that the total cost and carbon footprint of the system are affected by the dual factors of the 
TABLE 8: The carbon footprint of the main links in the cold chain logistics system.

\begin{tabular}{lcc}
\hline Link & Type & Carbon footprint \\
\hline $\begin{array}{l}\text { The carbon footprint of } \\
\text { the place of origin }\end{array}$ & - & $210\left(10^{-3} / \mathrm{kgcO}_{2}\right)$ \\
$\begin{array}{l}\text { Distribution center (per } \\
\text { unit product) }\end{array}$ & $\begin{array}{c}\text { Electronic power } \\
\text { Corruption treatment }\end{array}$ & $0.2125\left(10^{-3} / \mathrm{kgco}_{2}\right)$ \\
& - & $41.25\left(10^{-3} / \mathrm{kgcO}_{2}\right)$ \\
& & $208.5(55 \mathrm{~km} / \mathrm{h})$ \\
Refrigerated truck & Fuel consumption & $234.8(60 \mathrm{~km} / \mathrm{h})$ \\
transportation & & $234.5(70 \mathrm{~km} / \mathrm{h})$ \\
& & $312.0(90 \mathrm{~km} / \mathrm{h})$ \\
& & $339.5(100 \mathrm{~km} / \mathrm{h})$ \\
\hline
\end{tabular}

speed of the refrigerated truck and distance coefficient $\beta$. It can be seen from Figures 2 and 3 that, with the increase of the distance coefficient $\beta$, the overall trend of changes in the total cost of the system and the total carbon emissions is roughly the same. When the speed of refrigerated trucks gradually increases, the total cost of the system and the total carbon emissions of the system both show a downward trend.

5.2.1. Analysis of the Impact of Speed of Refrigerated Truck on Total Cost and Carbon Footprint. According to the life cycle theory, the life cycle analysis of the circulation process of the fresh product $\mathrm{A}$ is carried out to clarify the calculation boundary of the carbon footprint of the logistics model. The Matlab 2016 analysis software is used to optimize the solution, and the relevant parameters of the system are substituted into the model calculation. The analysis results of the impact of a single factor on the system are as follows.

It can be seen from Figure 4 that changes in the speed of refrigerated trucks have a certain impact on the total cost and carbon footprint of the system. Within a certain range, as the transportation speed increases, the total cost and the carbon footprint have a downward trend. Among them, the carbon footprint and the speed of refrigerated vehicles have an approximate quadratic function, that is, the carbon footprint changes with the speed of refrigerated vehicles, and the optimal solution of the carbon footprint can be found in the current system model. When the speed of refrigerated trucks increases from $55 \mathrm{~km} / \mathrm{h}$ to $90 \mathrm{~km} / \mathrm{h}$, the carbon footprint and total system cost are gradually decreasing. When the speed of the refrigerated truck is equal to $90 \mathrm{~km} / \mathrm{h}$, both the carbon footprint and the total system cost are minimized. After that, the carbon footprint showed an upward trend, while the total system cost hardly changed.

By analyzing the data in the figure, it can be obtained that when the speed of the refrigerated truck is greater than $90 \mathrm{~km} / \mathrm{h}$, the total carbon footprint shows an upward trend. Considering that the processing of spoiled fresh products will produce a larger carbon footprint, the unit cost of processing spoiled fresh products in this system is relatively large, so the total system cost at this time is slowly decreasing. Compared with the increase in carbon footprint, the decrease in total cost is even smaller. At this time, based

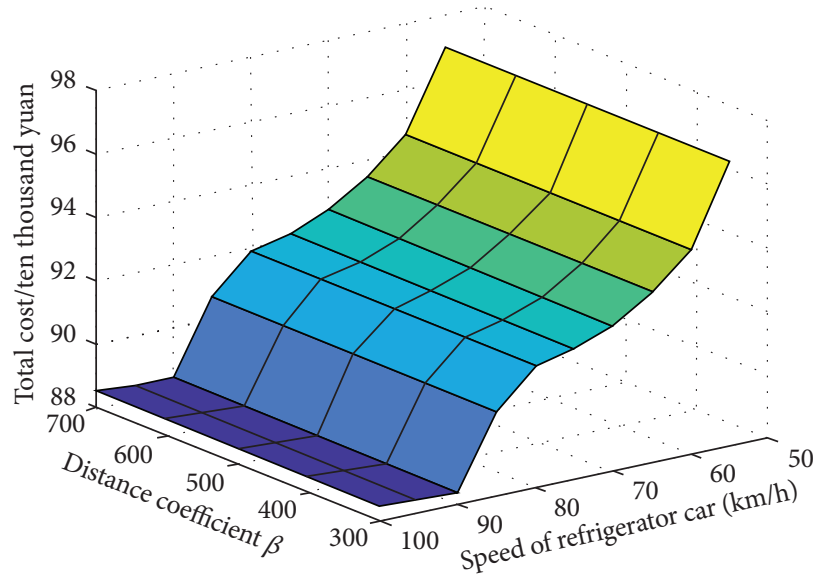

Figure 2: Changes in total cost due to dual factors.

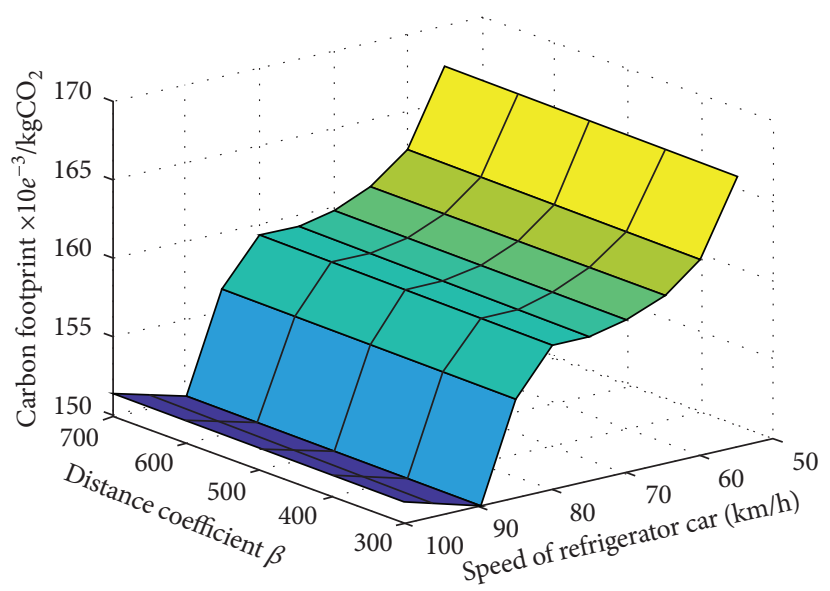

FIgURE 3: Changes in carbon footprint due to dual factors.

on the perspective of energy saving and emission reduction, it is recommended that companies adjust the speed of refrigerated trucks to $90 \mathrm{~km} / \mathrm{h}$.

5.2.2. Analysis of the Impact of the Expectation Rate of Freshness in the Retail Market on the Total Cost and Carbon Footprint. Fresh products have higher requirements for the timeliness of transportation because of high requirements for the freshness expectation from consumers when fresh products reach the terminal retail market. Because there is a negative correlation between freshness and transit time, in order to reduce the loss of fresh products in the transportation process, the cold chain transportation model was created. The system made a systematic analysis of the impact of total cost and carbon footprint on the basis of ensuring freshness.

It can be seen from Figure 5 that as the requirements for freshness when fresh products reach the terminal retail market continue to increase, the total carbon footprint shows a continuous increasing trend. The increasing range in the initial period is not obvious. The higher the freshness expectation rate, the larger increasing range in the carbon footprint. The total cost presents a trend that fluctuates 


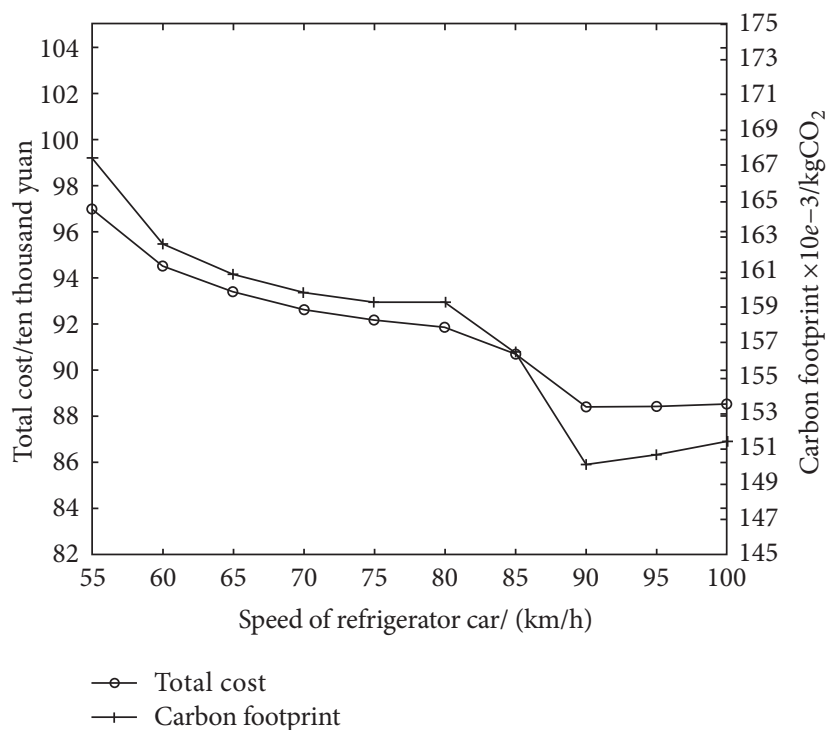

FIgURE 4: The impact of different speeds of refrigerated trucks on the total system cost and carbon footprint.

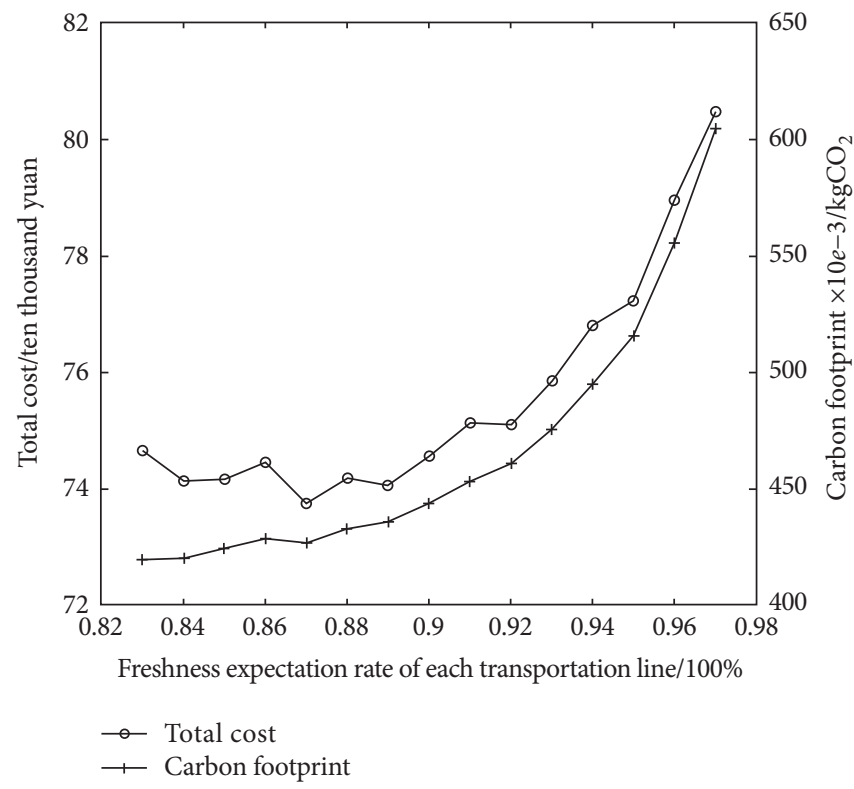

FIGURE 5: The impact of freshness expectation rate on total cost and carbon footprint.

firstly and then rises sharply as the freshness expectation rate increases. When the system requires fresh products to reach the end retail market with a freshness of 0.87 , the total cost of the system is minimized, and the increase in carbon footprint is not obvious. After that, with the increase in freshness requirements, the total cost fluctuated and increased, and the total carbon footprint also began to increase significantly. By analyzing the simulation results of the system, it can be known that, in actual transportation, from the perspective of economic benefits, the company operating fresh product A should consider adjusting the speed of refrigerated trucks so as not only to ensure the freshness of the fresh products when they reach the terminal retail market but also to save the total cost as much as possible.
5.2.3. Analysis of the Impact of Distance Coefficient $\beta$ on Total Cost and Carbon Footprint. When discussing the impact of the distance coefficient $\beta$ on the total cost and carbon footprint of the system, the amount of damage of the distribution center must be considered when using rail and road transportation. The average speed of road transportation is assumed to be $60 \mathrm{~km} / \mathrm{h}$. The average speed of railway transportation is $150 \mathrm{~km} / \mathrm{h}$, and the unit cost of handling corrupted fresh products in the distribution center is 3 yuan $/ \mathrm{kg}$.

According to existing research, it can be known that, with other unchanged conditions, the product carbon footprint caused by railway transportation is only $55 \%$ of that of road transportation. It can be seen from Figure 6 that, with the increase of the distance coefficient, it means 


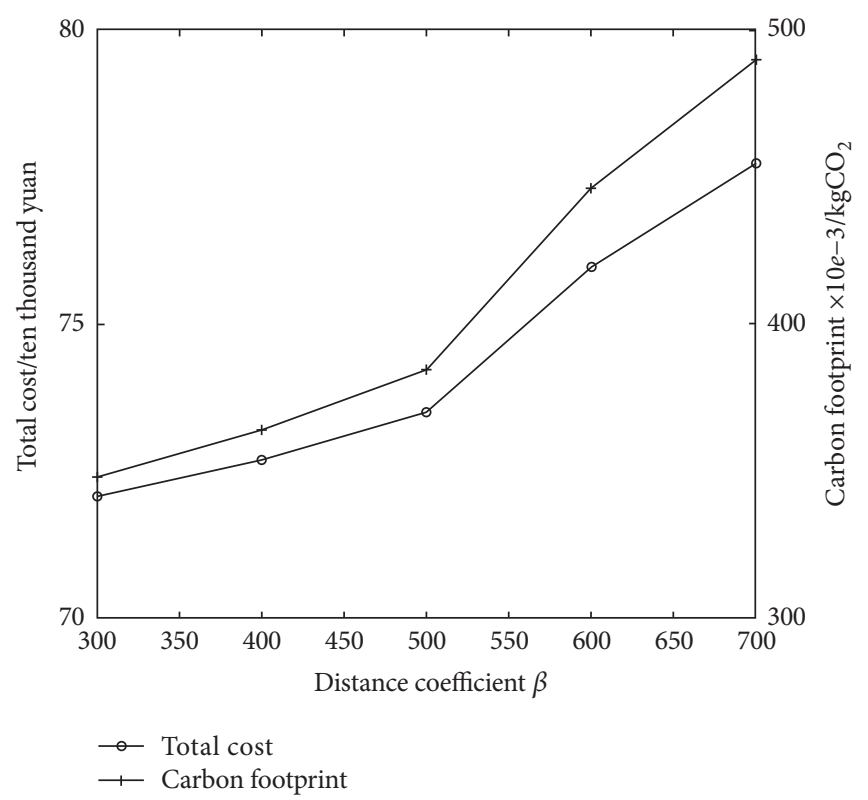

Figure 6: The impact of distance coefficient on the total cost and carbon footprint.

that road transportation is adopted when the transportation distance is less than it, and the total cost and carbon footprint both show an increasing trend. In the distance range of $300-500 \mathrm{~km}$, the change in carbon footprint and total system cost has not increased much. When it exceeds $500 \mathrm{~km}$, the carbon footprint and total system cost increase sharply. From the perspective of carbon footprint, when it comes to long-distance distances, railway transportation should be chosen as the main mode. Long-distance railway transportation combined with short-distance road transportation is conducive to the sustainable development of logistics enterprises.

\section{Conclusion}

(1) From the simulation calculation and analysis results of the cold chain logistics carbon footprint model, it can be seen that, compared to other links in cold chain logistics, the refrigerated transportation link is the major carbon emitter of this circulation channel. Without considering the changes of other external uncertain factors, the speed of refrigerated trucks has a key impact on the carbon footprint. By analyzing the system simulation results, it can be seen that when the refrigerated truck travels at a speed of $90 \mathrm{~km} / \mathrm{h}$, the total cost is already at the lowest level. More importantly, the carbon footprint is minimized at this time and environmental benefits can be maximized.

(2) The freshness requirement has a more significant impact on the carbon footprint. When the freshness gradually increases from 0.83 , it can be seen that the total carbon footprint is significantly increased compared to the carbon emissions when there is no requirement for freshness. The higher the freshness requirement, the greater the increase in carbon footprint. When the freshness requirement is 0.87 , the total cost is minimized, and the increase in the carbon footprint is within an acceptable range. Therefore, appropriately limiting the freshness of the cold chain logistics system to about 0.87 can meet the requirements of the terminal market for freshness, and, at the same time, the environmental and economic benefits of cold chain logistics are balanced.

(3) At present, Chinese cold chain circulation rate is still less than 30\%. Compared with developed countries, there is a huge potential for the development in Chinese cold chain logistics industry. Through this study, it is found that, for cold chain logistics practitioners, sometimes economic and environmental benefits cannot achieve the optimal combination at the same time. For example, when the carbon footprint of the system is the lowest, the total cost may not always be optimal. In response to this situation, it is recommended that relevant national departments establish and improve corresponding laws and regulations as soon as possible. The implementation of subsidies for enterprises that actively implement energy conservation and emission reduction has a positive guiding effect on the sustainable development of the cold chain logistics industry and also eliminates the worries of relevant enterprises about making choices between economic benefits and environmental costs.

\section{Data Availability}

The data used to support the findings of this study are included within the article. 


\section{Conflicts of Interest}

The authors declare that there are no conflicts of interest regarding the publication of this paper.

\section{Acknowledgments}

This work was sponsored by the Ministry of Education Humanities and Social Sciences Planning Foundation of China (Grant no. 19YJA790028), Key Lab of Information Network Security of Ministry of Public Security (Grant no. C20609), Municipal Key Curriculum Construction Project of University in Shanghai (Grant no. S202003002), and Practical Teaching Construction Project of Shanghai University of Engineering Science (Grant no. P202003001).

\section{References}

[1] Z. Liu, L. L. Lang, B. Hu et al., "Emission reduction decision of agricultural supply chain considering carbon tax and investment cooperation," Journal of Cleaner Production, vol. 294, Article ID 126305, 2021.

[2] J. Y. Chen and H. Huang, "Study on current status and countermeasures of cold chain for fresh agricultural products based on E-commerce," Science and Technology Management Research, vol. 3506, pp. 179-183, 2015.

[3] Y. Q. Wang, Y. Zhou, and R. Zhang, "A review of the research methods on influencing factors of carbon emissions and carbon footprint," Environmental Engineering, vol. 35, pp. 155-159, 2017.

[4] L.-Y. Zhang, M.-L. Tseng, C.-H. Wang, C. Xiao, and T. Fei, "Low-carbon cold chain logistics using ribonucleic acid-ant colony optimization algorithm," Journal of Cleaner Production, vol. 233, pp. 169-180, 2019.

[5] X. Ke, "Study on development of agricultural products cold chain logistics under low carbon economy," Logistics Engineering and Management, vol. 40, pp. 4-5, 2018.

[6] Z. Liu, B. Hu, Y. Zhao et al., "Research on intelligent decision of low carbon supply chain based on carbon tax constraints in human-driven edge computing," IEEE Access, vol. 8, pp. 48264-48273, 2020.

[7] V. G. Lo-Iacono-Ferreira, R. Viñoles-Cebolla, and M. J. Capuz-Rizo, "Transport of Spanish fruit and vegetables in cardboard boxes: a carbon footprint analysis," Journal of Cleaner Production, vol. 244, p. 118784, 2020.

[8] N. S. Kim, M. Janic, and B. Van Wee, "Trade-off between carbon dioxide emissions and logistics costs based on multiobjective optimization," Transportation Research Record: Journal of the Transportation Research Board, vol. 2139, no. 1, pp. 107-116, 2009.

[9] G. Y. Qin, F. M. Tao, and L. X. Li, “A vehicle routing optimization problem for cold chain logistics considering customer satisfaction and carbon emissions," International Journal of Environmental Research and Public Health, vol. 16, 2019.

[10] Z. Wang, L. Leng, S. Wang, G. Li, and Y. Zhao, "A hyperheuristic approach for location-routing problem of cold chain logistics considering fuel consumption," Computational Intelligence and Neuroscience, vol. 2020, p. 17, 2020.

[11] C. Beretta, P. J. R. Cronje, S. Hellweg et al., "Environmental trade-offs in fresh-fruit cold chains by combining virtual cold chains with life cycle assessment," Applied Energy, vol. 254, Article ID 113586, 2019.
[12] M. Bortolini, M. Faccio, E. Ferrari et al., "Fresh food sustainable distribution: cost, delivery time and carbon footprint three-objective optimization," Journal of Food Engineering, vol. 174, pp. 56-67, 2015.

[13] Z. Y. Tian, L. Zhou, and R. P. Yuan, "The newsvendor problem under carbon cap-and-trade mechanism," Systems Engineering, vol. 35, pp. 88-94, 2017.

[14] Z. Liu, S. Chen, B. Hu, M. Zhou, and Y. Zhao, "Research on staged pricing model and simulation of intelligent urban transportation," IEEE Access, vol. 7, pp. 141404-141413, 2019.

[15] G. Hu, X. Mu, M. Xu, and S. A. Miller, "Potentials of GHG emission reductions from cold chain systems: case studies of China and the United States," Journal of Cleaner Production, vol. 239, p. 118053, 2019.

[16] H. Moncer, A. Rami, and A. Shamayleh, "Integrated economic and environmental models for a multi stage cold supply chain under carbon tax regulation," Journal of Cleaner Production, vol. 166, pp. 1357-1371, 2017.

[17] Z. Yao and Y. Zhang, "Research on the optimization of cold chain logistics distribution route under internet of things and low carbon," Ecological Economy, vol. 36, pp. 61-66, 2020.

[18] Z. Liu, Q. Xu, and K. Yang, "Optimal independent pricing strategies of dual-channel supply chain based on risk-aversion attitudes," Asia-Pacific Journal of Operational Research (APJOR), vol. 35, no. 2, pp. 1-17, 2018.

[19] L. Yang and G. T. Zhang, "The closed-loop supply chain network decision based on corporate environmental criteria and consumer's environmental consciousness," China population, Resource and Environment, vol. 29, no. 11, pp. 71-81, 2019.

[20] S. D. Wei, "Differential game analysis on supply chain's strategy of carbon emission reduction $\mathrm{R} \& \mathrm{D}$ under carbon trading policy," Chinese Journal of Management Science, vol. 15, no. 5, pp. 782-790, 2018.

[21] M. Efthymiou and A. Papatheodorou, "EU emissions trading scheme in aviation: policy analysis and suggestions," Journal of Cleaner Production, vol. 237, Article ID 117734, 2019.

[22] B. Daria, C. Martina, I. Ilaria et al., "Sustainability in material purchasing: a multi-objective economic order quantity model under carbon trading," Sustainability, vol. 10, no. 12, p. 4438, 2018.

[23] Z. Liu, H. X. Guo, H. Guo et al., "Research on the optimized route of cold chain logistics transportation of fresh products in context of energy-saving and emission reduction," Mathematical Biosciences and Engineering, vol. 18, no. 2, pp. 1926-1940, 2021.

[24] D. L. Jiang and X. L. Yang, "Genetic algorithm for continuous location problem of physical distribution center for decaying products," Systems Engineering-Theory \& Practice, vol. 2, pp. 62-67, 2003. 